\title{
Advancing Research in School Mental Health: Introduction of a Special Issue on Key Issues in Research
}

\author{
Steven W. Evans $\cdot$ Sharon H. Stephan • \\ George Sugai
}

Published online: 14 May 2014

(c) Springer Science+Business Media New York 2014

This introductory article and the following four articles constitute a special issue of School Mental Health focused on issues in research in this multidisciplinary and complicated field of study. Although many unique constraints are associated with conducting research in this field, many rich opportunities exist to better the lives of students with emotional and behavioral problems. This introductory article and those that follow describe some of these limitations and opportunities. To provide some context for these scholarly reviews and discussions, we begin by providing an overview of the recent history of school mental health $(\mathrm{SMH})$ and then describe some of the challenges facing investigators in this field.

\section{Recent History of School Mental Health}

Researchers and practitioners agree that children with emotional and behavioral problems experience serious difficulties at school and that research intended to improve our understanding and ability to enhance outcomes is critically important. These viewpoints, however, were not always widely accepted until Eli Bower conducted groundbreaking work to address these issues in the 1950s. His early definition of "emotionally disturbed" (Bower,

S. W. Evans $(\square)$

Ohio University, Athens, OH, USA

e-mail: evanss3@ohio.edu

S. H. Stephan

University of Maryland School of Medicine, Baltimore, MD,

USA

G. Sugai

University of Connecticut, Storrs, CT, USA
1960) became the model for the initial version of the Education for Handicapped Children Act of 1977. ${ }^{1}$ In addition, his research in California provided important evidence for including services for these children in this legislation. The Education for Handicapped Children Act established in schools formal infrastructure and due process safeguards for the delivery of interventions to students with emotional and behavioral problems. Bower's research and advocacy efforts are recognized as critical groundwork for establishing SMH practice and research.

Following Bower's accomplishments, research efforts in the 1980s and 1990s focused on identifying and understanding the learning and behavior characteristics of these students and the nature of their school-related impairment (e.g., Atkins, Pelham \& Licht, 1985; Walker, Shinn, O’Neill \& Ramsey, 1987). As our knowledge base grew, school-based prevention models were developed and studied, and screening procedures, early intervention strategies, and assessment-based interventions were developed and validated (e.g., Cowen et al., 1996; Kauffman \& Landrum, 2009; Rutherford, Quinn, \& Mathur, 2004; Walker, Ramsey, \& Gresham, 2004; Walker, Severson, Feil, Stiller \& Golly, 1998).

In her book, "Full Service Schools: A Revolution in Health and Social Services for Children, Youth, and Families," Joy Dryfoos (1994) described how schools could be a place where all students, especially students with emotional and behavioral problems, could receive comprehensive services. Many mental health and education professionals throughout the country worked together during these decades to build models of $\mathrm{SMH}$ services using a variety of funding sources (Evans et al., 2003). The

\footnotetext{
1 The notable exception to Bower's contribution to this act is the social maladjustment clause in the legislation that Bower and others have long criticized (see Bower, 1982; Cloth et al. (2013).
} 
first national SMH conference was in 1995 in Baltimore and was attended by professionals from a diverse group of disciplines. The meeting was sponsored by the University of Maryland Center for School Mental Health (CSMH) under the leadership of Mark Weist and with federal funding support from the Health Resources and Services Administration. Professionals from a variety of disciplines established foundational research and practice that launched the field of SMH.

Several federal policy efforts also shaped and advanced SMH efforts. The Surgeon General report of 1999 (U.S. Department of Health and Human Services, 1999) and supplement to the report in 2001 (Satcher, 2001) highlighted both the tremendous need for services and poor access to care in the children's mental health arena and identified schools as a primary site for receiving mental health care. Researchers have documented that schools indeed are the primary site for mental health service provision among children and adolescents (Burns et al., 1995). The President's New Freedom Commission Report (2003) also pointed to the value of school-based mental health services, listing the "expansion of school mental health programs" as one of its 19 final recommendations to transform the national mental health system across the life span.

Two additional federally funded reports increased national interest in and support for SMH. The first of these is the Annapolis Coalition released the Action Plan on Behavioral Health Workforce Development (2007), a culmination of a two-year strategic planning process involving more than 5,000 individuals across the nation. This effort was funded by three centers within the Substance Abuse and Mental Health Services Administration and identified schools as a critical venue for enhancing our nation's behavioral health workforce (Hoge et al., 2007). Second, in 2009, the Institute of Medicine report, Preventing Mental, Emotional, and Behavioral Disorders Among Young People: Progress and Possibilities, documented the longitudinal impact of several school-based social-emotional-behavioral interventions, further bolstering public interest in integrating mental health supports into schools (O'Connell, Boat, \& Warner, 2009). Transformative efforts in the children's mental health system have been informed by these milestones. For example, a rise in federal and state legislation increased funding and procedural requirements for schools and communities to support student mental health (Stephan, Weist, Kataoka, Adelsheim, \& Mills, 2007).

In education in 1996, the reauthorization of the Education of Individuals with Disabilities Act legislated an increase in technical assistance supports to state and local education agencies that would enhance the education of students with emotional and behavioral problems in schools. As a result, the National Center on Positive
Behavioral Interventions and Supports was established, and over the last 16 years has refined and validated a behavior support and technical assistance framework designed to improve the adoption and implementation of evidencebased behavioral interventions. This framework has core features that align well with SMH: (a) universal screening, (b) continuous progress monitoring, (c) team-driven databased coordination and problem solving, (d) evidencebased behavioral interventions that are integrated into a continuum of support, (e) sustained and scalable implementation fidelity, and (f) cultural and contextual responsiveness (Sugai et al. 2000; Walker et al. 1996) (www.pbis. org, Center on Positive Behavioral Interventions and Supports). In recent years, the positive behavior support framework has proven to be useful for enhancing the selection, organization, and delivery of evidence-based behavioral practices and systems in schools and more importantly for improving how SMH services can be organized (see Sugai \& Stephan, 2014).

Research in intervention development and evaluation of SMH services has also advanced over the last two decades by funding and policy from the Office of Special Education Programs and after 2002 from the Institute of Education Sciences (IES). IES has become the primary funding source at the US Department of Education for the scientific study of SMH services and other school-related research. In the US Department of Health and Human Services, the National Institute of Health (NIH) also has a history of funding SMH research. In particular, the National Institute of Mental Health and National Institute of Child Health and Human Development have funded many intervention development research projects and randomized clinical trials. Other federal and state agencies and foundations have also funded this research, but IES and NIH have played a central role.

\section{Challenges in Research in School Mental Health}

Despite advancements in policy, funding, research, and legislation, the integration of schools and mental health must address a number of disciplinary obstacles (Horner et al., 2005; Kern, Evans \& Lewis, 2011) related to, for example, (a) theoretical or conceptual perspective (e.g., psychoanalytic vs. behavioral, medical vs. educational, cognitive vs. behavioral), (b) research designs (e.g., group vs. single subject, qualitative vs. quantitative), (c) service delivery approaches (e.g., educational vs. clinical, special education vs. counseling/psychology), and (d) interdisciplinary preparation (e.g., social work vs. psychology, school vs. clinical psychology, counseling vs. teaching).

Although not insurmountable, formal efforts are needed for consensus-building, collaboration, and integration to 
enable a functional integration of education and mental health into SMH research and practice. For example, one strength of research in the field of SMH is the multidisciplinary teams of investigators who conduct research, transfer research to practice, and develop policy to support implementation. These collaborations have led to the critical re-examination of common practices, such as providing accommodations to students with emotional and behavioral disorders (Harrison, Bunford, Evans, \& Owens, 2013), as well as, innovative models for service provision that integrate education and mental health services (Kern, Evans, \& Lewis, 2011). Historically, research in SMH was published within the discipline-specific journals of the investigators who conducted the research (e.g., special education, school psychology, and clinical child psychology). This journal is an example of an outlet where a variety of disciplines are represented on the editorial board, within the list of reviewers, across published authors, and by the types of published topics and research.

By necessity, practitioners seem quicker to embrace a multidisciplinary approach to SMH than researchers. Addressing the momentary, hourly, and daily needs of students with emotional and behavioral disorders in schools requires constant collaboration across discipline lines and continues when these students must navigate situations outside the classroom walls (e.g., neighborhoods, home, work, and leisure and recreation). Thus, not surprisingly, national SMH conferences sponsored by the CSMH at the University of Maryland have attracted hundreds of practitioners and policy makers every year wanting to learn the latest practices; however, relatively few researchers have attended. To increase attendance by researchers, in 2012 Sharon Stephan (Co-Director of the CSMH) and Steven Evans initiated a School Mental Health Research Summit that met the day prior to the national conference. Many of the most productive researchers in the area of SMH were invited to discuss how SMH is defined and described, what a program of SMH research should address, and how researchers and practitioners would collaborate effectively and efficiently across disciplines and perspectives. The third summit is scheduled for 2014 and is sponsored by the CSMH (University of Maryland), Center for Intervention Research in Schools (Ohio University), and Springer Publishing.

\section{Intervention Development}

Much of the research conducted in SMH is focused on the development and evaluation of interventions for children and adolescents with emotional and behavioral problems in schools and can be organized according to the three tiers associated within the Positive Behavioral Interventions and Supports framework. As such, this intervention research focuses on prevention, targeted interventions, and intensive services, as well as methods to measure the need for these services and a student's response to them. Much of this research focuses on indices of effectiveness, feasibility, and acceptability.

Although a discussion of the definitions of effectiveness, feasibility, and acceptability is beyond the scope of this article, one issue that pertains to all of them is the tendency in our field to discuss them as dichotomous categories instead of the continua that they really represent. For example, interventions are typically represented as either or not: evidence based and empirically supported, feasible, and acceptable. The threshold for determining one classification or another is often arbitrary and fraught with methodological challenges. For example, many intervention studies include an evaluation of school personnel implementing interventions, who are usually the teachers or SMH professionals who agreed to participate in the study. Acceptability and feasibility ratings are completed by these same individuals, and the percentages who adequately endorse the acceptability or feasibility of an intervention are reported (based on whatever rating scale is used in the study). As a result, most interventions described in the literature are found to be acceptable and feasible. The problem with that conclusion is that the people who did not participate in the study (possibly because, for example, they did not believe that the intervention was feasible or acceptable) were never asked. Thus, we have a skewed representation of intervention feasibility and acceptability because of a favorably biased sample of respondents.

In addition, individual thresholds for determining and classifying levels of effectiveness, feasibility, and acceptability are highly variable. For example, if one-third of the sample in a large intervention trial improves to a meaningful degree and move into the normal range, the evidence-based nature of that intervention could remain unclear. On the one hand, helping a third of all students with a given problem could be valuable to large numbers of children and families. On the other hand, a SMH professional who is considering use of that intervention with an individual child who is similar to the study sample may question whether the intervention will work with that child. Furthermore, although an intervention considered unacceptable and infeasible by $90 \%$ of SMH professionals could be cast aside as impractical, yet that same intervention could be applied effectively by the other $10 \%$ of SMH professionals, resulting in improved functioning for many children with serious problems. Our dichotomization of the terms effectiveness, feasibility, and acceptability seriously limits communication, intervention selection, and potential student benefit, especially for new techniques.

Finally, we are concerned that feasibility and acceptability are sometimes held as priorities over effectiveness. 
Returning to the example of the intervention for which only $10 \%$ of all SMH professionals find feasible and acceptable, the effectiveness of that intervention must be evaluated carefully before considering adoption and implementation in applied settings. If that intervention is associated with moderate improvements for children with serious impairment and no other similarly effective alternatives are available, then considering that intervention may be important, especially, if implementation and progress monitoring can be implemented. In other healthcare areas, feasibility and acceptability are not so exclusively prioritized. For example, the development of the X-ray machine was not dismissed because hospitals or physicians' offices did not have space and staff was not adequately trained. Instead, space was arranged, staff was prepared, X-rays were taken, and care was advanced. Currently, many SMH professionals and educators are not held accountable to select and implement evidence-based practices with integrity and consideration for individual student characteristics. In fact, studies have revealed that a large portion of schools engage in activities intended to help students with problem behavior, but do so inconsistently and with poor quality (Gottfredson \& Gottfredson, 2002). To improve the lives of children with emotional and behavioral problems, the system may need to be changed to enhance accountability for selecting best practices, implementing with integrity, collecting data to monitor progress, and making intervention decisions based on those data. If we do not change, we may be casting many " $\mathrm{x}$-ray machines" aside by over-prioritizing feasibility and acceptability in our business-as-usual approach.

\section{Special Issue on Research in School Mental Health}

At the 2012 summit, the idea, focus, and format of this special issue of the journal were conceptualized. After presentations and discussions, many participants expressed concern that key issues of SMH research needed additional attention. Summit participants identified areas that were critically important to establishing a working identity for SMH research, with particular attention on methodology, dissemination, and implementation. Specific topics within these areas included: (a) establishing working relationships across disciplines in complex educational settings; (b) documenting and communicating the important relationship between SMH and academic success; (c) identifying effective designs and strategies for SMH research as well as feasible, reliable, and valid measures; and (d) identifying and conducting research on solutions that are relevant and doable in applied settings. Each of the following four articles addresses one of these critical topics.
Writing teams comprised of researchers and graduate students who attended the summit were formed to deepen descriptions, understanding, challenges, and future research around these identified areas. These teams were unique in that many of the authors had not met prior to the 2012 summit, were representing perspectives from diverse disciplines (i.e., education, school psychology, clinical child psychology, and social work), and did not necessarily have a history of formal product-focused collaboration. A positive outcome of the summit was many hours of followup conference calls, email communications, and shared editing of drafts that led to new conversations and questions and ultimately the articles in this special issue.

In sum, excellent progress has been made in our discipline-specific research and dissemination efforts; however, more is needed. To improve outcomes for all students and, in particular, for students with emotional and behavioral disorders, researchers must (a) take advantage of the fact that every child participates in a formal institution called "schools" and (b) integrate our disciplinary perspectives to improve the content, organization, implementation, and impact of evidence-based practices and systems. The articles in this special issue of School Mental Health provide excellent discussion and direction relative to the unique mental health challenges facing students, schools, families, and communities and researchers and practitioners who bring discipline-specific research training and experience to an interconnected system of SMH.

\section{References}

Atkins, M. S., Pelham, W. E., \& Licht, M. H. (1985). A comparison of objective classroom measures and teacher ratings of attention deficit disorder. Journal of Abnormal Child Psychology, 13(1), 155-167.

Bower, E. (1960). Early Identification of Emotionally Disturbed Children in School. Springfield, IL: Charles C Thomas.

Bower, E. (1982). Defining emotional disturbance: Public policy and research. Psychology in the Schools, 19, 55-60.

Burns, B. J., et al. (1995). Children's mental health service use across service sectors. Health Affairs, 14(3), 147-159.

Cloth, A.H., Evans, S.W., Becker, S.P. \& Paternite, C.E. (2013). Social maladjustment and special education: State regulations and continued controversy. Journal of Emotional and Behavioral Disorders. doi:10.1177/1063426613487405.

Cowen, E. L., Hightower, A. D., Pedro-Carroll, J. L., Work, W. C., Wyman, P. A., \& Haffey, W. G. (1996). School-Based Prevention for Children at Risk. Washington DC: American Psychological Association.

Dryfoos, J. G. (1994). Full-Service Schools: A Revolution in Health and Social Services for Children, Youth, and Families. San Francisco: Jossey-Bass Publishers.

Evans, S. W., Glass-Siegal, M., Frank, A., Van Trueren, R., Lever, N., \& Weist, M. (2003). Overcoming the challenges of funding school mental health programs. In M. Weist, S. Evans, \& N. 
Lever (Eds.), Handbook of School Mental Health: Advancing Practice and Research. New York: Kluwer/Plenum.

Gottfredson, D. C., \& Gottfredson, G. D. (2002). Quality of schoolbased prevention programs: Results from a national survey. Journal of Research in Crime and Delinquency, 39, 3-35.

Harrison, J., Bunford, N., Evans, S. W., \& Owens, J. S. (2013). Educational accommodations for students with behavioral challenges: A systematic review of the literature. Review of Educational Research, 83, 551-597.

Hoge, M. A., Morris, J. A., Daniels, A. S., Stuart, G. W., Huey, L. Y., \& Adams, N. (2007). An Action Plan for Behavioral Health Workforce Development. Cincinnati, Ohio: Annapolis Coalition on the Behavioral Health Workforce.

Horner, R. H., Carr, E. G., Halle, J., McGee, G., Odom, S., \& Wolery, M. (2005). The use of single-subject research to identify evidence-based practice in special education. Exceptional Children, 71(2), 165-179.

Kauffman, J. M., \& Landrum, T. J. (2009). Characteristics of Emotional and Behavioral Disorders of Children and Youth (9th ed.). Upper Saddle River, NJ: Merrill Prentice-Hall.

Kern, L., Evans, S. W., \& Lewis, T. (2011). Description of an iterative process for intervention development. Education and Treatment of Children, 34, 593-617.

O’Connell, M. E., Boat, T., \& Warner, K. E. (Eds.). (2009). Preventing Mental, Emotional, and Behavioral Disorders Among Young People: Progress and Possibilities. Washington, DC: National Academies Press.

Rutherford, R. B, Jr, Quinn, M. M., \& Mathur, S. R. (Eds.). (2004). Handbook of Research in Emotional and Behavioral Disorders. New York: Guilford Press.

Satcher, D. (2001). Mental health: Culture, race, and ethnicity-A supplement to mental health: A report of the surgeon general. Retrieved from http://www.surgeongeneral.gov/library/mental health/cre/execsummary-3.html.
Stephan, S., Weist, M., Kataoka, S., Adelsheim, S., \& Mills, C. (2007). Transformation of children's mental health services: The role of school mental health. Psychiatric Services, 58(10), $1330-1338$.

Sugai, G., et al. (2000). Applying positive behavior support and functional behavior assessment in schools. Journal of Positive Behavior Interventions, 2, 131-143.

Sugai, G., \& Stephan, S. (2014). Considerations for a school mental health implementation framework. In S. Barrett, L. Eber, \& M. Weist (Eds.), Advancing Education Effectiveness: Interconnecting School Mental Health and School-Wide Positive Behavior Support (pp. 18-33). Eugene: OSEP Technical Assistance Center on Positive Behavioral Interventions and Supports. University of Oregon.

U.S. Department of Health and Human Services (1999). Mental Health: A Report of the Surgeon General. Rockville, MD: U.S. Department of Health and Human Services, Substance Abuse and Mental Health Services Administration, Center for Mental Health Services, National Institutes of Health, National Institute of Mental Health.

Walker, H. M., et al. (1996). Integrated approaches to preventing antisocial behavior patterns among school-age children and youth. Journal of Emotional and Behavioral Disorders, 4, 193-256.

Walker, H. M., Ramsey, E., \& Gresham, F. M. (2004). Antisocial Behavior in School: Evidence-Based Practices. Belmont, CA: Thomson/Wadsworth.

Walker, H. M., Severson, H. H., Feil, E. G., Stiller, B., \& Golly, A. (1998). First Step to Success: Intervening at the point of school entry to prevent antisocial behavior patterns. Psychology in the Schools, 35(3), 259-269.

Walker, H. M., Shinn, M. R., O’Neill, R. E., \& Ramsey, E. (1987). A longitudinal assessment of the development of antisocial behavior in boys: Rationale, methodology, and first-year results. Remedial and Special Education, 8(4), 7-16. 